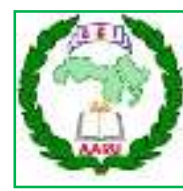

مجلة اتحاد الجامعات العربية للعلوم الزراعية، جامعة عين شمس، القاهرة، مصر

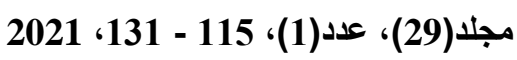

منة الله ممدوح حسن * - محمد بلير العراقي - محمد صلاح قنديل

قسم الاقتصاد الزراعي - كلية الزراعة - جامعة عين شمس - ص.ب 68 - حدائق شبرا 11241 - القاهرة -

مصر

*Corresponding author: menammdouh26@gmail.com

من لوغاريتم إنفاق الأسرة السنوي على السلع الغذائية

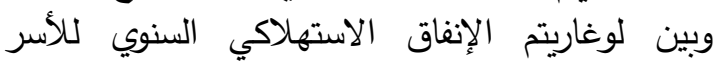

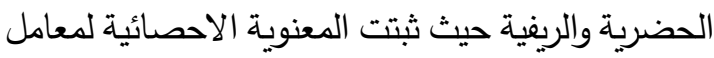

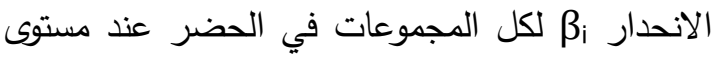

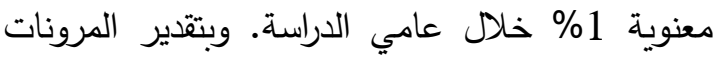

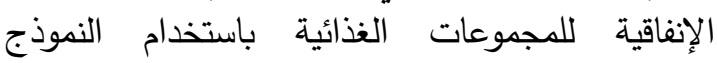

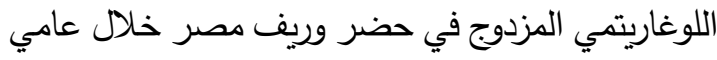

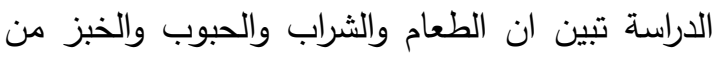
السلع الضرورية بينما اللحوم من السلع شبه الكبات الكمالية. وبمقارنة المرونات الإنفاقية للمجموعات الفئح الغذائية للنموذجين في حضر وريف مصر تبين النين أن المرونة

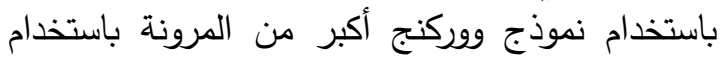

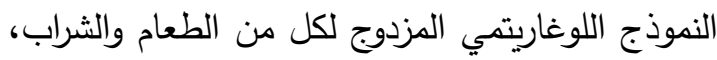

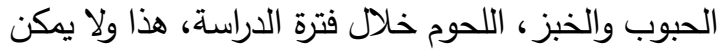

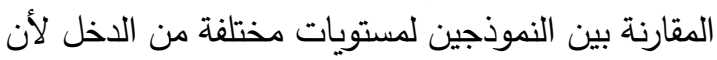
النموذج اللوغاريتمي المزدوج يعطى تقدير واحد فقط لانط للمرونة لا يعتمد على مستوى الدخل.

الكلمات المفتاحية: الإنفاق، الاستهلاك، الانحدار، وكروكات

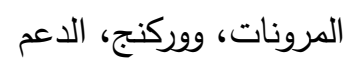

\section{1}

تهتم الدولة بالعمل على توفير السلع الغذائية الأساسية لجميع فئات المجتمع نظرا لأهمية الغذاء للحياة البشرية وذلك من خلال إتباع العديد من السياسات

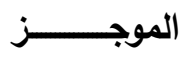

استهدف البحث دراسة أنماط الإنفاق الاستهلاكي

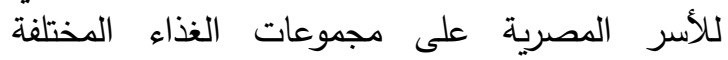
باستخدام نموذجين إحصائيين هما نموذج ولئين

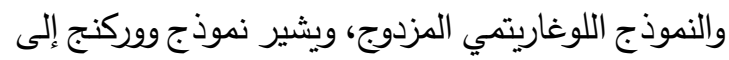
وجود علاقة عكسية بين نسب الإنفاق على السلع الغذائية

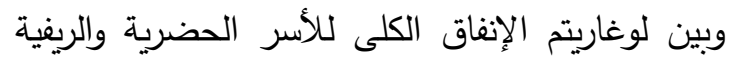

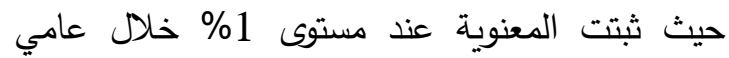
الدراسة 2015، 2018/2017، كما تبين زيادة متوسط الإنفاق السنوي للأسر الحضرية من 37433 جنيه عام

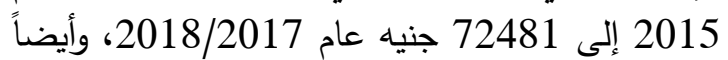
زيادته للأسر الريفية من 33956 جنيه عام 2015 الى 2015 إلى عائ 62297.95 جنيه عام 2018/2017 كما تبين زيادته للفئات الانفاقية المختلفة في الحضر والريف خلال عالمي عامي

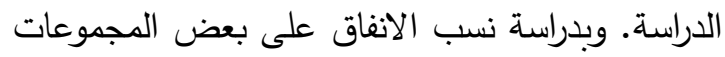

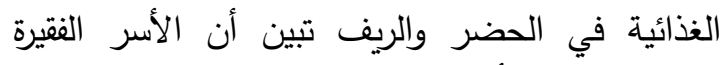

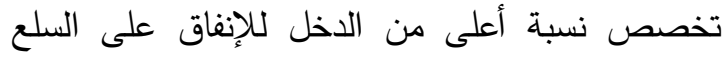

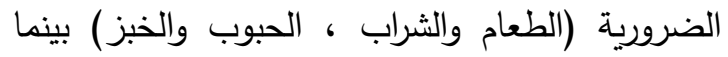

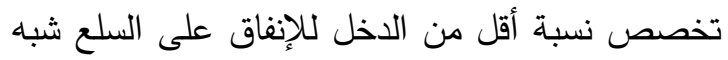
الكمالية (اللحوم) وبدراسة المرونات الإنفاقية باستخدام

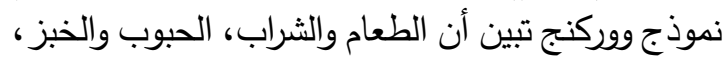

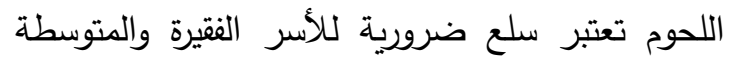

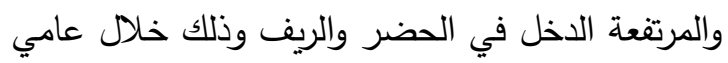

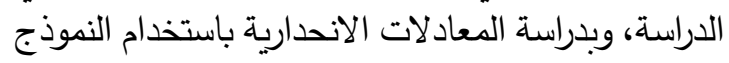
اللوغاريتمي المزدوج تبين وجود علاقة طردية بين كل 


$$
\text { منة الله - العراقي - قنديل }
$$

\section{3 أهداف البحث}

يهذف البحث إلى رصد التغيرات في أنماط استهلاك

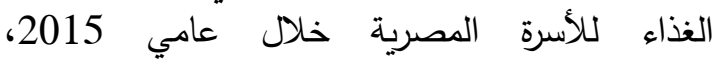
2018/2017 وذلك من خلال النقاط التالية: 1-دراسة تطور أوجه وأنماط الإنفاق الاستهلاكي

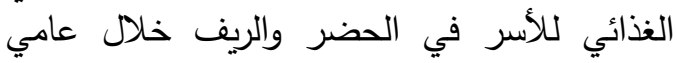

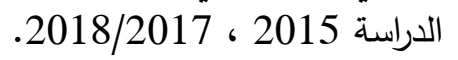

2-تقدير المرونات الانفاقية لبعض المجموعات الغذائية للأسر الحضرية والريفية خلال عامي الدراسة 2015، لإنية 2018/2017

3- المقارنة بين نتائج نموذج ووركنج ونتائج النموذج اللوغاريتمي المزدوج.

\section{4 الطريقة البحثية ومصادر البيانات}

اعتمد البحث علي استخدام البيانات الإحصائية

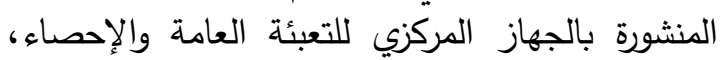

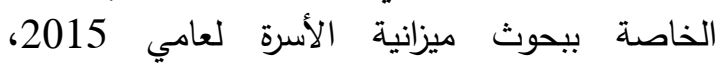
2018/2017، وذلك لحساب الإنفاق السنوي للأسر الأنس

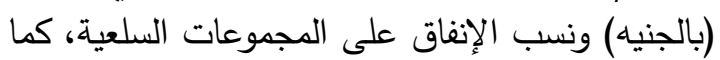

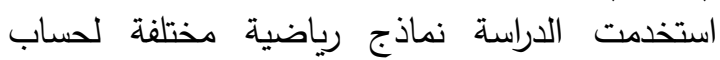
المرونات الانفاقية للأسر على المجموعات الغذائية في حضر وريف مصر، ولقدات تلم التركيز على التى ثلاث

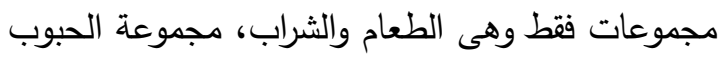
والخبز باعتبار أنها تشمل سلع أساسية لاستهلاكلك الأسر

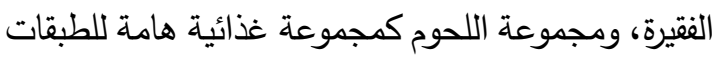

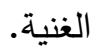

\section{5 نتائج البحث}

1.5 أوجه وأنماط الانفاق الاستهلاكي في الحضر

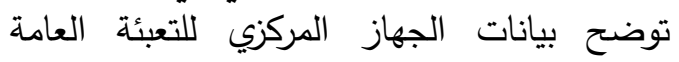
والإحصاء أن متوسط الإنفاق السنوي للأسر في الحضر العربئ

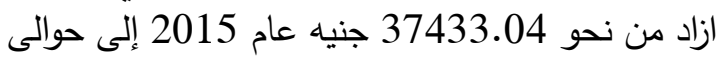

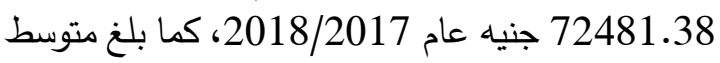
الإنفاق السنوي للأسر الفقيرة التي تتمثل في الفئات

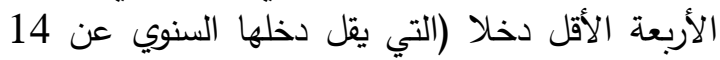
الف جنيه) نحو 11491 جنيه، بينما بلغ متوسط الإنفاق دئ
الاقتصادية مثل دعم رغيف الخبز وبطاقات التموين

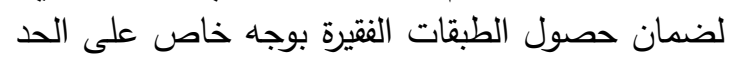

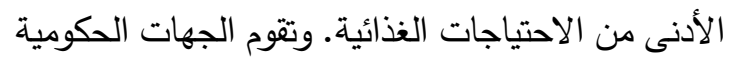

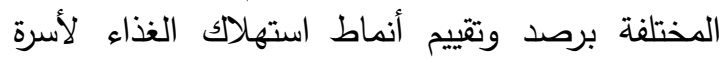

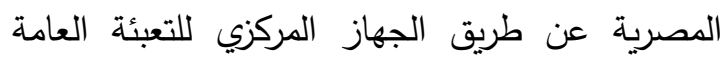
والإحصاء الذي يقوم بإجراء البحوث المئن الميدانية للدخل

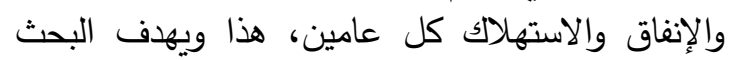
الحالي إلى الإلى الإقوف على كلى التغيرات في في الإنفاق

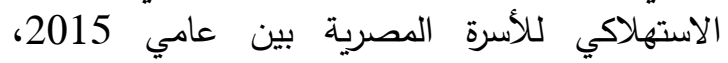

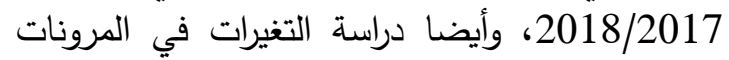

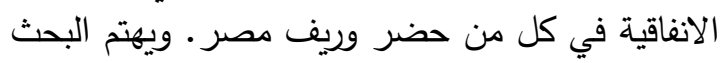
بدراسة الاختلافات في أنماط الإنفاق الاستهلاكي من فئة الأن

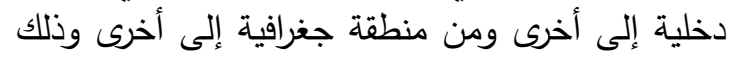

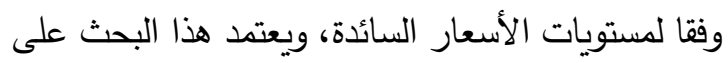

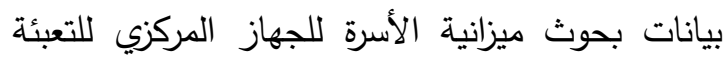

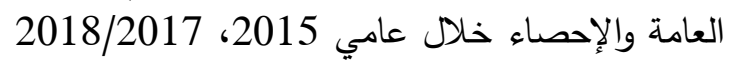
وذلك باستخدام نموذج ووركينج والنموذج اللوغاريتمي

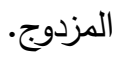

\section{2 مشكلة البحث}

تتبلور مشكلة البحث في رصد التغيرات في أنماط

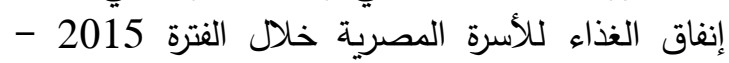
2018 اعتمادا على بحوث ميزانية الأسرة وتكمن أهمية الفردية

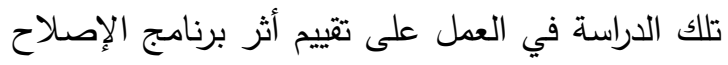
الاقتصادي الذى قامت الحكومة المصرية بتنفيذه اعتبارا

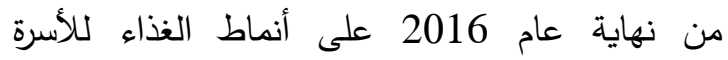

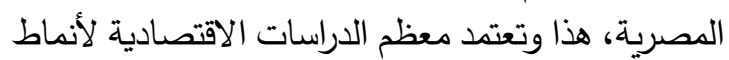

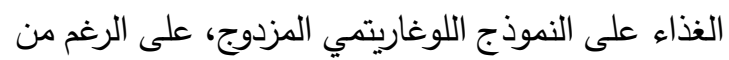

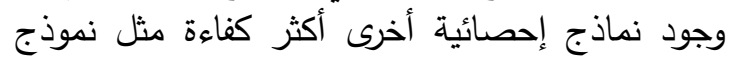
ووركنج، الذى يتم استخدامه بكثافة في الفترة الأخيرة في ألخاء

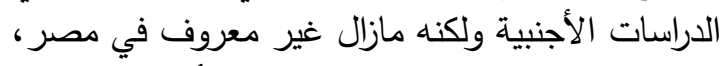

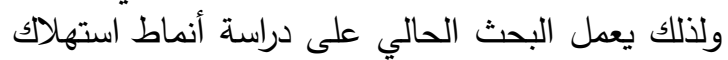

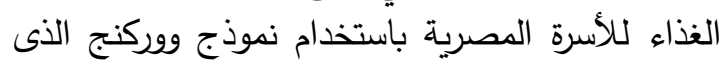

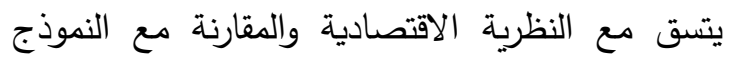

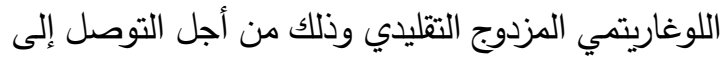

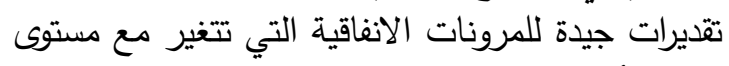

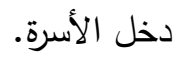


الأهمية النسبية للإنفاق عليها وتتمثل في مجموعة

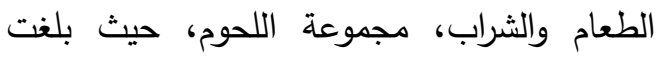

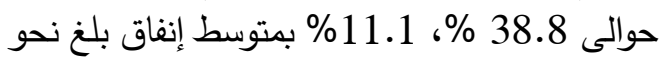
2015، 10772.3 2015، بينما بلغت الأهمية النسبية لمجموعة التبات

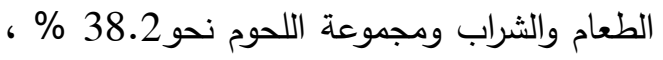
10.7 بمتوسط إنفاق بلغ حوالى 20539 ، 207.9

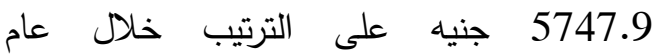
.2018/2017 3- بالنسبة للأسر مرتفعة الدخل فكانت مجموعة

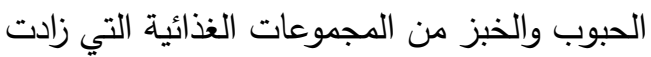

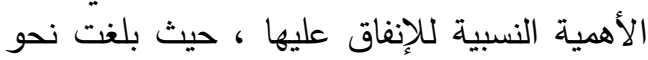

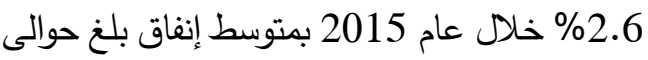
2014.4 جنيه ، بينما بلغت الأهمية النسبية للحبوب والخبز نحو 2.8\% بمتوسط إنفاق بلغ

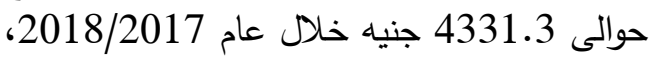
في حين قلت الأهمية النسبية للإنفاق على على النى

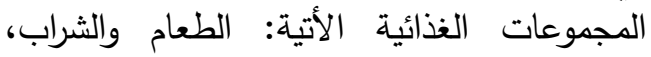
اللحوم، حيث بلغت حوالى 25.9\%، 89.4 بمتوسط إنفاق بلغ نحو جنيه على الترتيب خلال عام 2015، بينما بلغت الإن

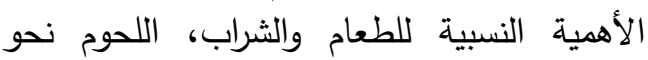
23.6\%، 76351.8 36351.8، عام 2017، 11862.1 جنيه على الترتيب خلال

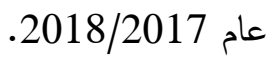

\section{5 أوجه وأنماط الإنفاق الاستهلاكي في الريف}

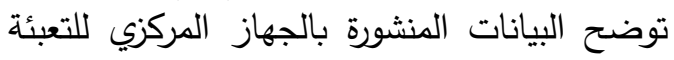

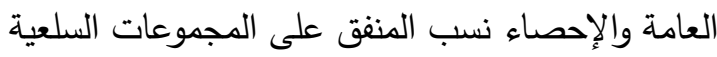
للأسرة الريفية، حيث الإداد متوسط الإنفاء لإنفاق السنوي للأسرة

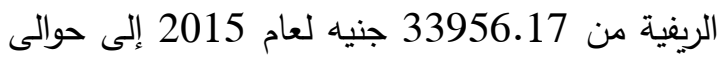

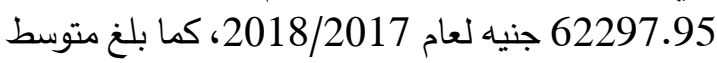

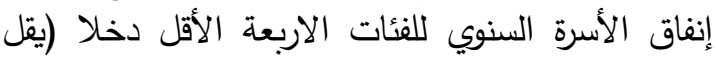

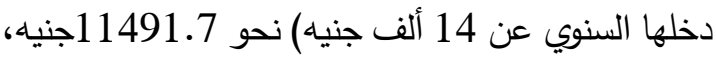
بينما الفئات متوسطة الدخل (24-30 ألف جنيه) فقد الفن بلغ متوسط إنفاق الأسرة السنوي لها حوالى 27548.25 جنيه، في حين بلغ ذلك المتوسط للفئ للفئات مرتفعة الدخل

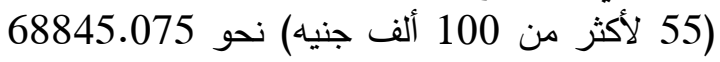
جنيه وذلك خلال عام 2015.
السنوي للأسر متوسطة الدخل التي تتمثل في الفئات الأربعة التي تتراوح دخولها بين (24-30 لأنونة ألف جنيه)

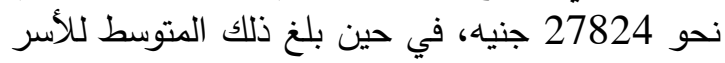

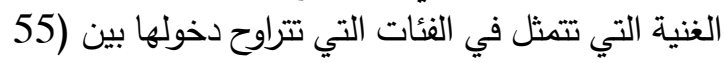
لأكثر من 100 ألف جنيه) نحو 2015 الغنية 84539 جنيه خلال عام 2015. بينما بلغ متوسط الإنفاق السنوي للأسر للفئات

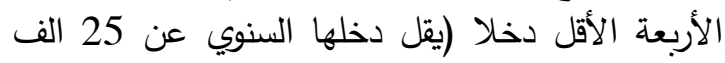
جنيه) نحو 18395 جنيه، بينما بلغ في الفئات متوسطة الأنس الدخل (45-60 ألف جنيه) نحو حين بلغ ذلك المتوسط للفئات مرتفعة الدخل (100-

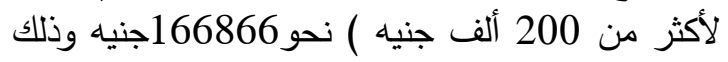
خلال عام 2018/2017. يوضح الجدولين 1، 2 أهم التغيرات في الأهمية

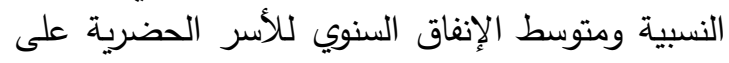

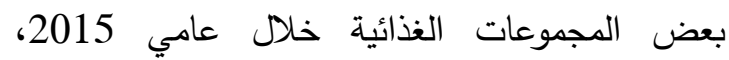
2018/2017 ، حيث يتبين من الجدولين الاتي: 1- بالنسبة للأسر الفقيرة كانت هناك مجموعات غلات غذائية

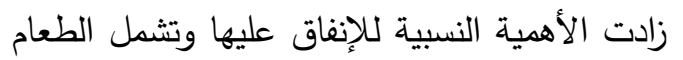

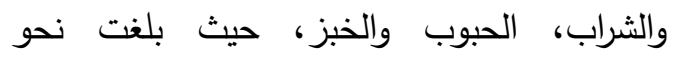

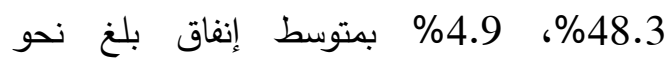

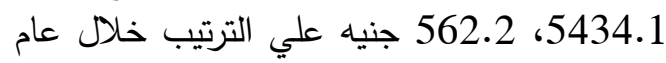
2015، بينما بلغت الأهمية النسبية للإنفاق على التربه

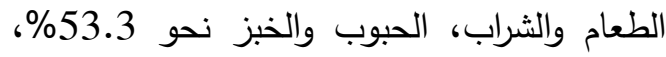

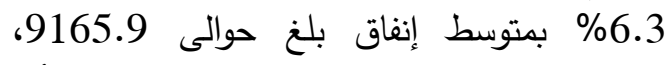
1097.7 جنيه خلال عام 2018/2017، أما بـان بالنسبة لمجموعة اللحوم فقد قلت الأهمية النسبية للإنفاق عليها حيث بلغت نحو 12.4\% بمتوسط النغ الإن

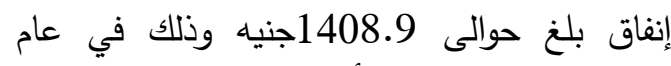
2015 ، بينما بلغت الأهمية النسبية للإنفاق علي ولي

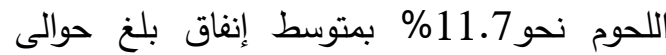

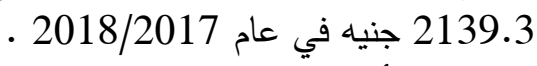
2- وبالنسبة للأسر متوسطة الاخل فكانت هنالك أيضا مجموعات غذائية زادت الأهمية النسبية للإنفاق

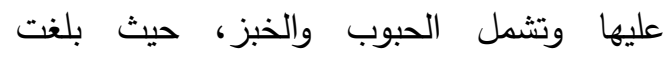
نحو4.4\% في عام 2015 بمتوسط إنفاق بلغ حوالى 1221 جنيه، بينما بلغت نحو بمتوسط إنفاق بلغ حوالى 2572.2 جنيه في عام

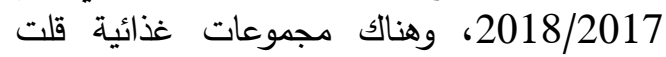




$$
\text { منة الله - العراقي - قنديل }
$$

جدول 1. الإنفاق السنوي والأهمية النسبية للإنفاق على المجموعات السلعية المختلفة لأسر الحضر عام 2015

\begin{tabular}{|c|c|c|c|c|c|c|c|c|}
\hline \multicolumn{4}{|c|}{ متوسط الانفاق السنوي للأسرة على المجموعات السلعية } & \multicolumn{4}{|c|}{ متوسط نسبة الانفاق على المجموعة } & \multirow{2}{*}{ 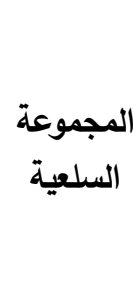 } \\
\hline الاسر مرتفعة & الالاستر & الاسر الفقيرة | & كل الاسر & الاسر مرتفعة & الالتوسطة & الفقيرة - الاسر & 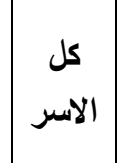 & \\
\hline 19972.13 & 10772.30 & 5434.13 & 11837.74 & 25.89 & 38.80 & 48.27 & 37.74 & 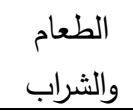 \\
\hline 2014.40 & 1221.05 & 562.15 & 1252.50 & 2.62 & 4.40 & 4.95 & 4.03 & 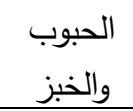 \\
\hline 6532.80 & 3078.00 & 1408.93 & 3555.79 & 8.37 & 11.08 & 12.41 & 10.72 & اللحوم \\
\hline
\end{tabular}

المصدر : جمعت وحسبت من جدول رقم 5 بالدراسة، والجهاز المركزي للتعبئة العامة والإحصاء، بحث الدخل والإنفاق

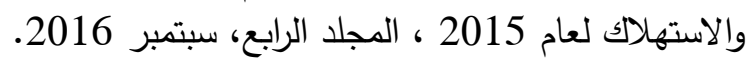

جدول 2. الانفاق السنوي والاهمية النسبية على المجموعات السلعية المختلفة لأسر الحضر عام 2018/2017

\begin{tabular}{|c|c|c|c|c|c|c|c|c|}
\hline \multicolumn{4}{|c|}{ متوسط الانفاق السنوي للأسرة على المجموعات السلعية } & \multicolumn{4}{|c|}{ متوسط نسبة الانفاق على المجموعة } & \multirow{2}{*}{ 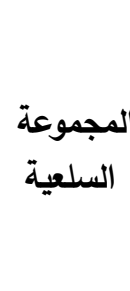 } \\
\hline الاسر مرتفعة & المتوسطة & الاسر الفقيرة & كل الاسر & الالفر & الالمتوسطة & |الفقيرة | الفر | & 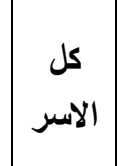 & \\
\hline 36351.80 & 20539.03 & 9165.90 & 21704.71 & 23.64 & 38.23 & 53.29 & 37.83 & 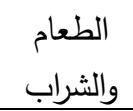 \\
\hline 4331.30 & 2572.20 & 1097.65 & 2620.82 & 2.79 & 4.79 & 6.26 & 4.57 & 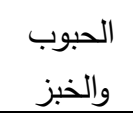 \\
\hline 11862.10 & 5747.88 & 2139.30 & 6409.66 & 7.66 & 10.67 & 11.74 & 10.14 & اللحوم \\
\hline
\end{tabular}

المصدر: جدعت وحسبت من جدول رقم 6 بالدراسة، والجهاز المركزي للتعبئة العامة والإحصاء، بحث الدخل والإنفاق والاستهلاك لعام 2018/2017 ، المجلد الرابع، يونيو 2019. 
3- بالنسبة للأسر مرتفعة الدخل فهناك مجموعات

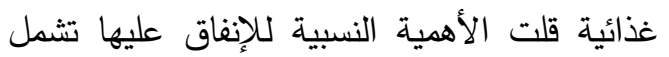

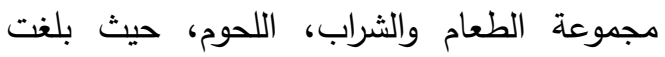

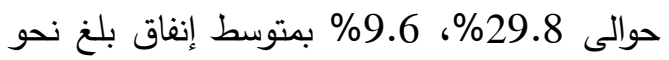

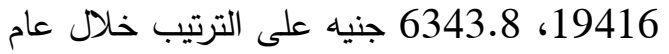
2015، بينما بلغت الأهمية النسبية للإنفاق على التى

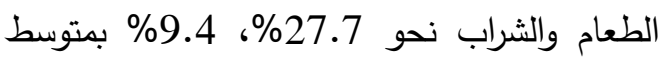
إنفاق بلغ حوالى 2018/2017، 32369.2 11019.4 جنيه خلال عام 2018/2017، بينما كانت الأهمية النسبية للإنفاق علي مجموعة الحبوب والخبز ثابتة نسبيا في كل من عامي 2015، 2018/2017.

3.5 التقدير الإحصائي للمرونات الإنفاقية باستخدام نموذج ووركنج يستخدم نموذج ووركنج لحساب التقدير الإحصائي للمرونات الإنفاقية للمجموعات السلعية المختلفة، ويمكن كتابة الثكل الرياضي لنموذج ووركنج كما يلى:

$$
W_{i}=\propto_{i}+\beta_{i} \operatorname{Ln} X
$$

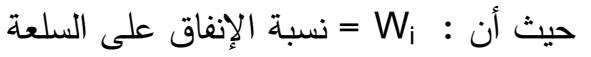
X ويتم حساب المرونة الإنفاقية للسلعة i في نموذج لإنفان ووركنج كالآتي:

$$
e_{i}=1+\left(\frac{\beta_{i}}{w_{i}}\right)
$$

حيث ان : ل W

$$
\text { i المرونة الإنفاقية للسلعة = e e }
$$

الاستهلاكي

ويتضح رياضيا أن السلعة i تعتبر ضرورية إذإذة كانت

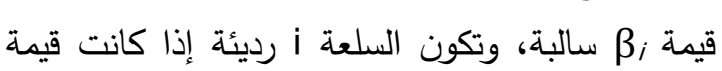
المقدار كانت قيمة i موجبة فإن السلعة i تكون كمالية كما هو متوقع في بعض السلع التي يقبل عليها الأغنياء مثل

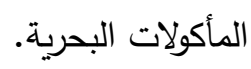

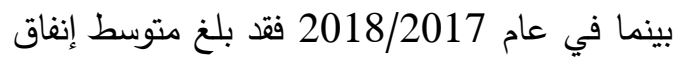
الأسرة السنوي للفئات الأربعة الأقل دخلا (يقل دخلها

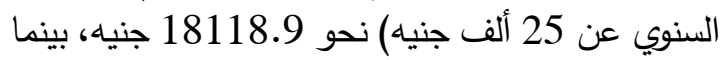
الفئات متوسطة الدخل (45-60-635 ألف جنيه) بلغت

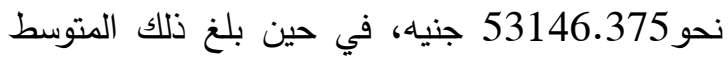
للفئات مرتفعة الدخل (100- لأكثر من 200 ألف فن فئ فئ جنيه) نحو 123307.37 جنيه. يوضح الجدولين 3، 3ن 4 أهم التغيرات في الأهمية

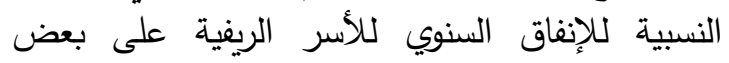

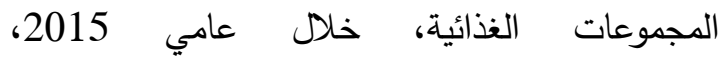
2018/2017 ويتبين من الجدولين الآتي: 1- بالنسبة للأسر الفقيرة فكانت هناك مجموعات الانين غذائية

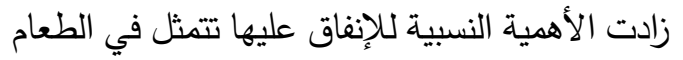

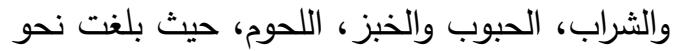

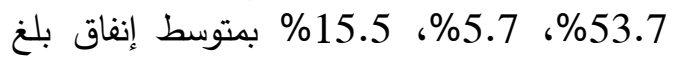

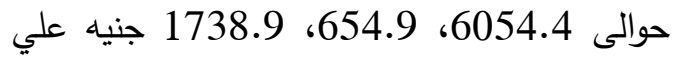
الترتيب خلال عام 2015، بينما بلغت الأهمية

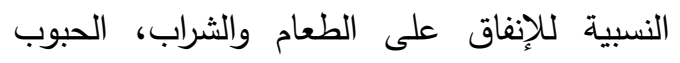

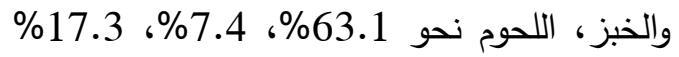
بمتوسط إنفاق بلغ حوالى 10210، 10210، 1262.8،

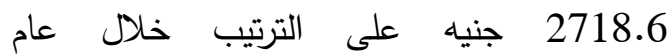
. 2018/2017 2- بالنسبة للأسر متوسطة الدخل فكانت هناك أيضا

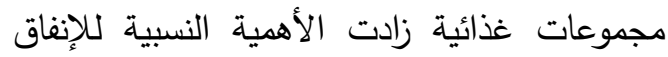

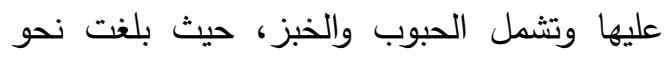

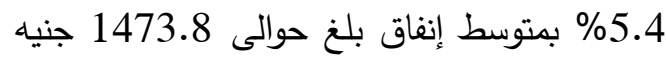
في عام 2015 ، بينما بلغت نحو 5.8 إنفاق بلغ عام

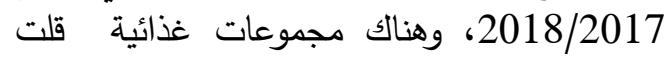

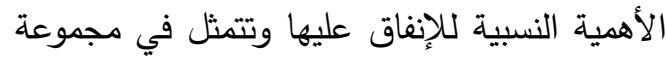

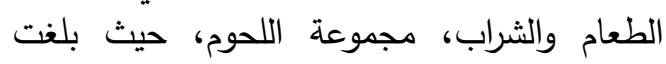

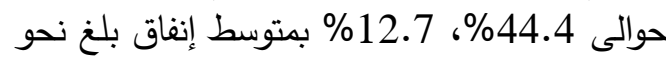
2197.6،

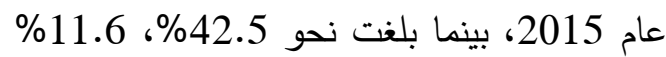
بمتوسط إنفاق بلغ نحو خلال عام 2018/2017. 


$$
\text { منة الله - العراقي - قنديل }
$$

جلول 3. الإنفاق السنوي والأهية النسبية للإنفاق على المجموعات السلعية المختلفة لأسر الريف عام 2015

\begin{tabular}{|c|c|c|c|c|c|c|c|c|}
\hline \multicolumn{4}{|c|}{ متوسط الانفاق السنوي للأسرة على المجموعات السلعية } & \multicolumn{4}{|c|}{ متوسط نسبة الانفاق على المجموعة } & \multirow{2}{*}{ 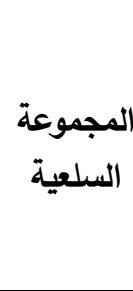 } \\
\hline الاسر مرتفعة & | الاسر المتوسطة & الاسر الفقيرة & كل الاسر & الآنر & الالاسترة & الفقيرة - - الاسر & 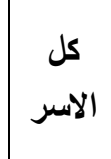 & \\
\hline 19416.05 & 12197.63 & 6054.38 & 12703.65 & 29.76 & 44.37 & 53.73 & 42.96 & 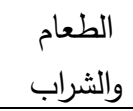 \\
\hline 2095.73 & 1473.85 & 654.95 & 1446.22 & 3.21 & 5.36 & 5.69 & 4.89 & 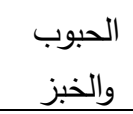 \\
\hline 6343.83 & 3495.80 & 1738.88 & 3861.39 & 9.64 & 12.70 & 15.50 & 12.66 & اللحوم \\
\hline
\end{tabular}

المصدر : جمعت وحسبت من جدول رقم 7 بالدراسة، والجهاز المركزي للتعبئة العامة والإحصاء، بحث الدخل والإنفاق والاستهلاك لعام 2015 ، المجلد الرابع، سبتمبر 2016.

جدول 4. الإنفاق السنوي والأهمية النسبية للإنفاق على المجموعات السلعية المختلفة لأسر الريف عام 2018/2017

\begin{tabular}{|c|c|c|c|c|c|c|c|c|}
\hline \multicolumn{4}{|c|}{ متوسط الانفاق السنوي للأسرة على المجموعات السلعية } & \multicolumn{4}{|c|}{ متوسط نسبة الانفاق على المجموعة } & \multirow{2}{*}{ 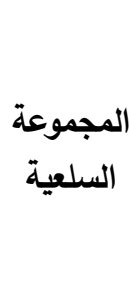 } \\
\hline الاسر مرتفعة & الالاسر الاخلة & الاسر الفقيرة & كل الاسر & الاسر مرتفعة & الالاسرة & | الفقيرة & 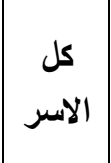 & \\
\hline 32369.20 & 22491.00 & 10209.50 & 22198.45 & 27.75 & 42.45 & 63.12 & 43.38 & 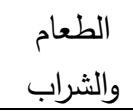 \\
\hline 3784.23 & 3084.88 & 1262.80 & 2847.41 & 3.25 & 5.83 & 7.37 & 5.54 & والخبز \\
\hline 11019.35 & 6186.00 & 2718.63 & 6615.01 & 9.41 & 11.65 & 17.34 & 12.34 & اللحوم \\
\hline
\end{tabular}

المصدر : جمعت وحسبت من جدول رقم 8 بالدراسة، والجهاز المركزي للتعبئة العامة والإحصاء، بحث الدخل والإنفاق والاستهلاك لعام 2018/2017، المجلد الرابع، يوليو 2019. 
الأسر الفقيرة والمتوسطة والمرتفعة الدخل في عام 2015

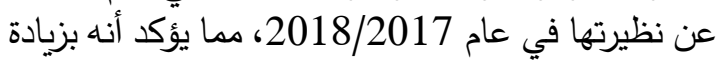
الدخول من عام لأخر تتخفض نسبة ما ينفق على الطعام

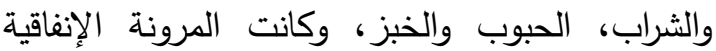

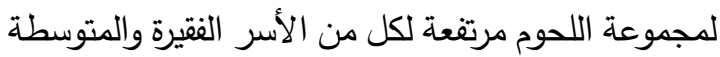

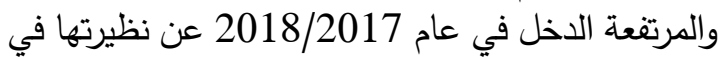

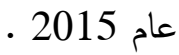

5.5 التقدير الإحصائي للمرونات الإنفاقية في الريف

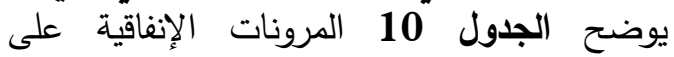
المجموعات الغذائية للريف خلال الفترة 2015، الأنافية 2018/2017 ، والتي تم حسابها باستخدام المعادلة رقم

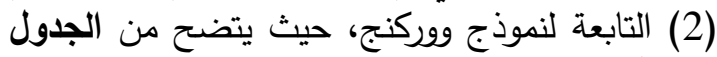

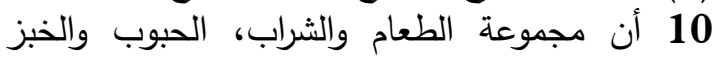

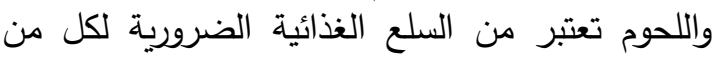

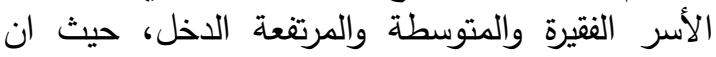

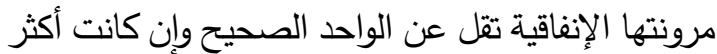

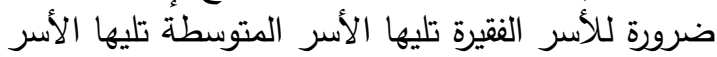

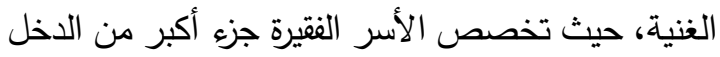

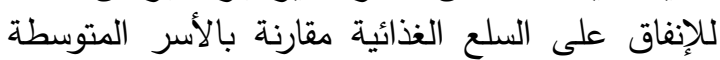

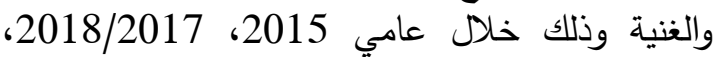
ويلاحظ انخفاض المرونة الإنفاقية للطعام والثراب، ولك، ولئ

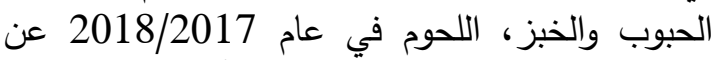
نظيرتها في عام 2015 ، مما يؤكد أنه بزيادة الدخول من عام لأخر تنخفض نسبة ما ينفق على السلع الغذائية.

6.5 التقدير الإحصائي للمرونات الإنفاقية باستخدام النموذج اللوغاريتمي المزدوج

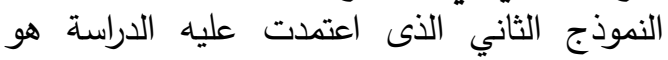

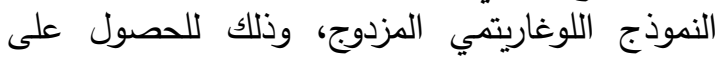

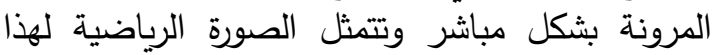
النموذج فيما يلي :

Lny $=\propto_{i}+\beta_{i} \operatorname{Ln} x$

حيث أن:

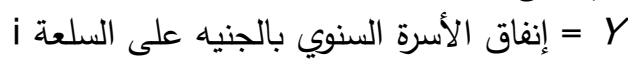
(بإنمالي الإنفاق الاستهلاكي السنوي للأسرة

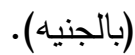

ويتم تقدير نموذج ووركنج لحساب المرونات الإنفاقية

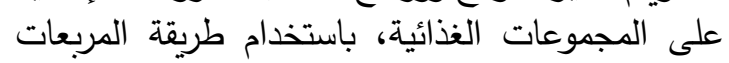

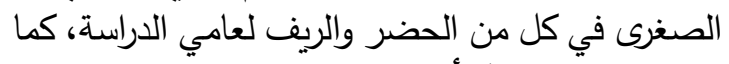

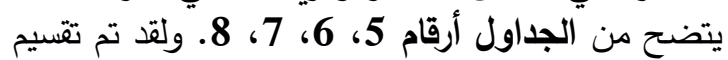

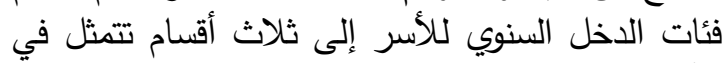

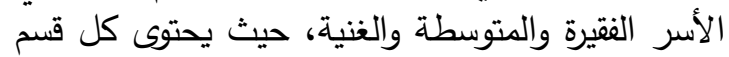

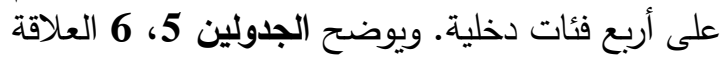

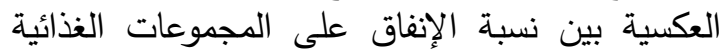

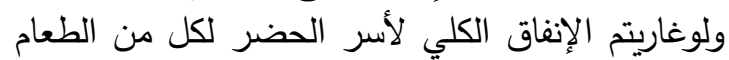

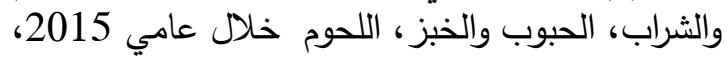

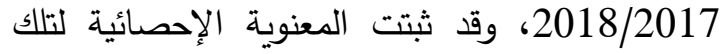

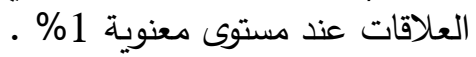

ويوضح الجدولين 7، 8 العلاقة العكسية بين نسبة

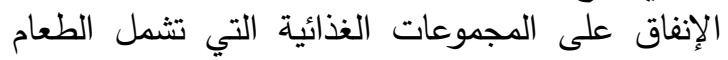

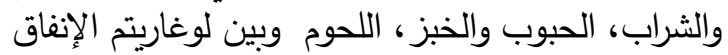

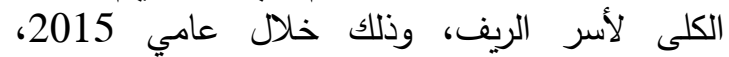

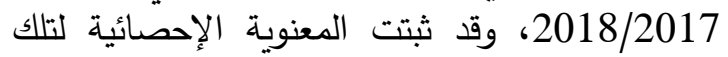

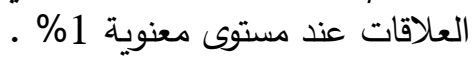

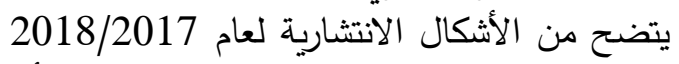

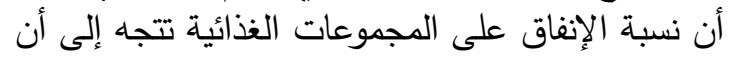

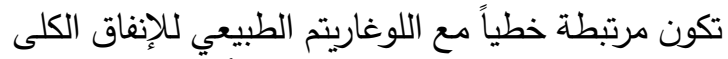

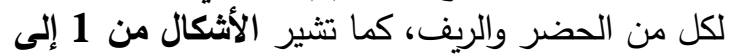

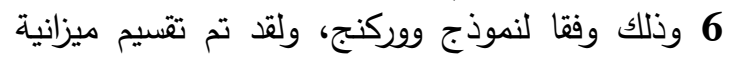
الأسرة إلى ثلاث مجموعات سلعية وهى كالآتي ولتئ : الطعام والشراب، الحبوب والخبز ، اللحوم.

4.5 التقدير الإحصائي للمرونات الإنفاقية في الحضر يوضح الجدول 9.

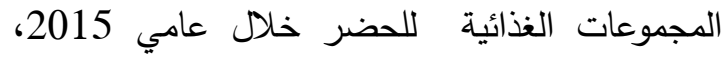
2018/2017، والتي تم حسابها باستخدام المعادلة رقم عالية

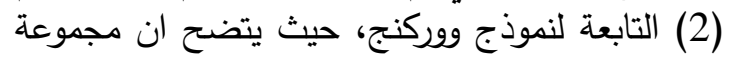

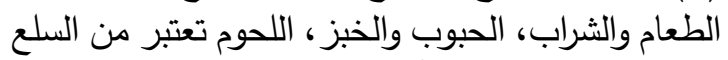

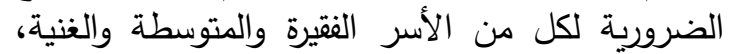

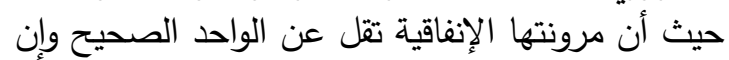
كانت أكثر ضرورة للأسر الفقيرة تليها الأسر المتوسطة الأنة

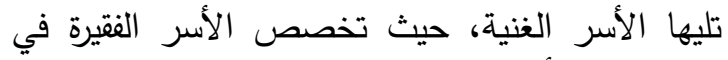
الحضر جزء أكبر من الدخل للإنفاق على السلح الغذائية الإنية مقارنة بالأسر المتوسطة والغنية وذلك الغناق خلال عامي الغذي الغية 2015، 2018/2017، ويلاحظ الخفاض والإنة المرونة الإنفاقية للطعام والشراب، والحبوب والخبز لكل من لخنط لكن 
جدول 5. المعادلات الانحدارية لنسب الإنفاق على المجموعات السلعية والإنفاق الكلى لأسر الحضر لعام 2015

\begin{tabular}{|c|c|c|c|}
\hline المجموعة السلعية & $\boldsymbol{R}^{2}$ & $\boldsymbol{F}$ \\
\hline الطعام والشراب & $W=\begin{array}{c}\text { (المعادلة } \\
(345.46-11.46 \operatorname{LnX})^{*}(-26.48)^{*}\end{array}$ & 0.97 & $701.08^{*}$ \\
\hline الحبوب والخبز & $\begin{array}{c}W=16.59-1.22 \operatorname{LnX} \\
(20.70)^{*}(-15.71)^{*}\end{array}$ & 0.93 & 246.69 \\
\hline اللحوم & $\begin{array}{c}W=32.09-2.08 \operatorname{LnX} \\
(15.81)^{*}(-10.55)^{*}\end{array}$ & 0.86 & 111.36 \\
\hline
\end{tabular}

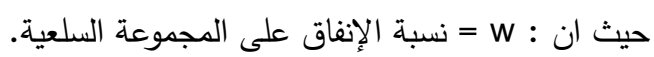

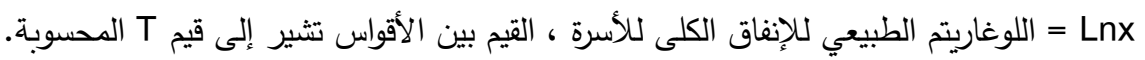

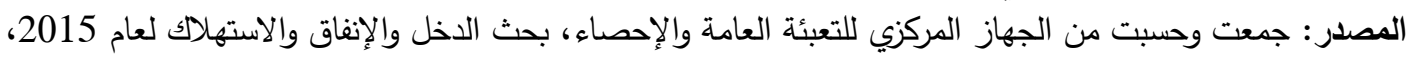
المجلد الرابع، سبتمبر 2016.

جدول 6. المعادلات الانحدارية لنسب الإنفاق على المجموعات السلعية والإنفاق الكلى لأسر الحضر لعام 2018/2017

\begin{tabular}{|c|c|c|c|}
\hline المجموعة السلعية & $\boldsymbol{R}^{2}$ & $\boldsymbol{F}$ \\
\hline الطعام والشراب & $\begin{array}{c}W=186.32-13.64 \operatorname{LnX} \\
(32.27)^{*}(-25.79)^{*}\end{array}$ & 0.97 & $665.01^{*}$ \\
\hline الحبوب والخبز & $\begin{array}{c}W=21.74-1.58 \operatorname{LnX} \\
(36.27)^{*}(-28.73)^{*}\end{array}$ & 0.98 & $825.31^{*}$ \\
\hline اللحوم & $\begin{array}{c}W=29.09-1.74 \operatorname{LnX} \\
(12.77)^{*}(-8.35)^{*}\end{array}$ & 0.80 & $69.69^{*}$ \\
\hline
\end{tabular}

حيث ان : w w سبة الإنفاق على المجموعة السلعية.

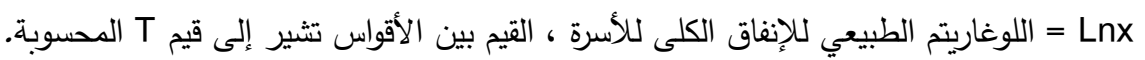

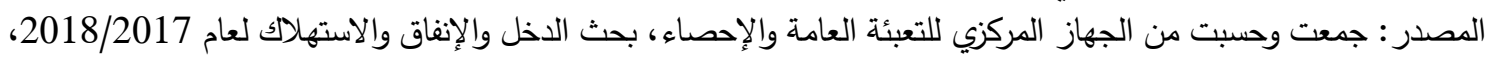
المجلد الرابع ، يونيو 2019

جدول 7. المعادلات الانحدارية لنسب الانفاق على المجموعات السلعية والانفاق الكلى لأسر الريف لعام 2015

\begin{tabular}{|c|c|c|c|}
\hline المجموعة السلعية & $\boldsymbol{R}^{2}$ & $\boldsymbol{F}$ \\
\hline الطعام والثراب & $\begin{array}{c}W=179.89-13.38 \operatorname{LnX} \\
(24.81)^{*}(-18.93)^{*}\end{array}$ & 0.95 & $358.21^{*}$ \\
\hline الحبوب والخبز & $\begin{array}{c}W=19.05-1.38 \operatorname{LnX} \\
(11.32)^{*}(-8.43)^{*}\end{array}$ & 0.79 & $71.08^{*}$ \\
\hline اللحوم & $\begin{array}{c}W=45.32-3.19 \operatorname{LnX} \\
(16.96)^{*}(-12.25)^{*}\end{array}$ & 0.89 & $149.94^{*}$ \\
\hline
\end{tabular}

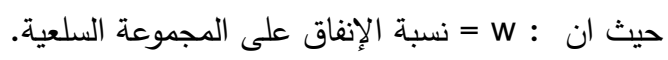

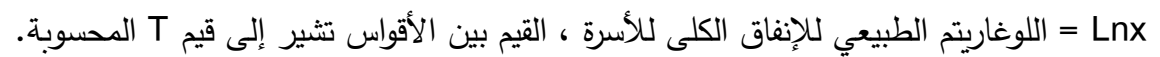

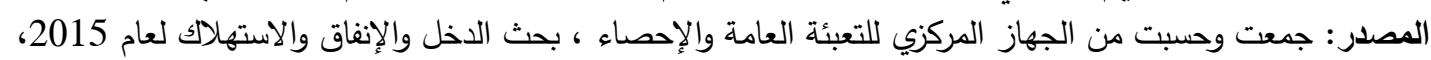

المجلد الرابع ، سبتمبر 2016. 
جدول 8. المعادلات الانحدارية لنسب الإنفاق على المجموعات السلعية والإنفاق الكلى لأسر الريف لعام 2018/2017

\begin{tabular}{|c|c|c|c|}
\hline المجموعة السلعية & $\boldsymbol{R}^{2}$ & $\boldsymbol{F}$ \\
\hline الطعام والثراب & $\begin{array}{c}W=249.31-19.06 \operatorname{LnX} \\
(16.54)^{*}(-13.69)^{*}\end{array}$ & 0.92 & $187.53^{*}$ \\
\hline الحبوب والخبز & $\begin{array}{c}W=27.66-2.05 \operatorname{LnX} \\
(16.25)^{*}(-13.02)^{*}\end{array}$ & 0.91 & $169.55^{*}$ \\
\hline اللحوم & $\begin{array}{c}(62.94-4.68 \operatorname{LnX} \\
(8.56)^{*}(-6.90)^{*}\end{array}$ & 0.74 & $47.64^{*}$ \\
\hline
\end{tabular}

حيث : w w سبة الإنفاق على المجموعة السلعية

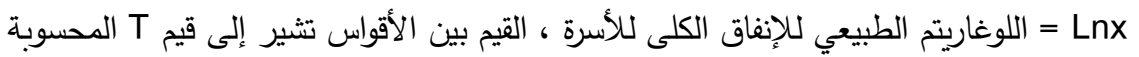

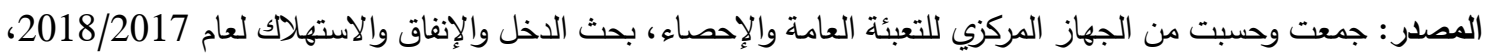
المجلد الرابع، يونيو 2019

جدول 9. المرونات الإنفاقية على المجمعات السلعية للحضر خلال عامي 2015 ، 2018/2017

\begin{tabular}{|c|c|c|c|c|c|c|c|c|}
\hline \multicolumn{4}{|c|}{ المرونات الانفاقية 2017 /2018 } & \multicolumn{4}{|c|}{ المرونات الانفاقية 2015} & \multirow[b]{2}{*}{ المجلعية الموعة } \\
\hline مرتفعة الاسر & الالاسر & الفقيرة & كل الاسر & الالاترة & متوسطة الاسر & الاسر الفقيرة & 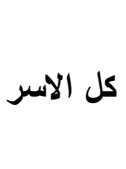 & \\
\hline 0.423 & 0.643 & 0.744 & 0.639 & 0.557 & 0.705 & 0.763 & 0.696 & الطعام والشراب \\
\hline 0.434 & 0.670 & 0.748 & 0.654 & 0.534 & 0.723 & 0.754 & 0.697 & الحبوب والخبز \\
\hline 0.773 & 0.837 & 0.852 & 0.828 & 0.751 & 0.812 & 0.832 & 0.806 & 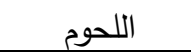 \\
\hline
\end{tabular}

المصدر: جمعت وحسبت من بيانات الجداول أرقام ( 1 ، 2 ، 5 ، 6 ).

جدول 10. المرونات الإنفاقية على المجموعات السلعية للريف عام 2018/2015،2017

\begin{tabular}{|c|c|c|c|c|c|c|c|c|}
\hline \multicolumn{4}{|c|}{ المرونات الانفاقية 2017 /2018 } & \multicolumn{4}{|c|}{ المرونات الانفاقية 2015} & \multirow[b]{2}{*}{ المجموعة السلعية } \\
\hline الالاتر & الالاستر & الالفقرة & الاسر & الآلفر & متوسطة الاسر & الفقيرة & 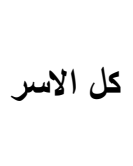 & \\
\hline 0.313 & 0.551 & 0.698 & 0.561 & 0.550 & 0.698 & 0.751 & 0.689 & الطعام والشراب \\
\hline 0.372 & 0.650 & 0.723 & 0.632 & 0.570 & 0.743 & 0.757 & 0.716 & الحبوب والخبز \\
\hline 0.503 & 0.598 & 0.730 & 0.621 & 0.669 & 0.749 & 0.794 & 0.748 & 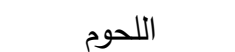 \\
\hline
\end{tabular}




$$
\text { منة الله - العراقي - قنديل }
$$

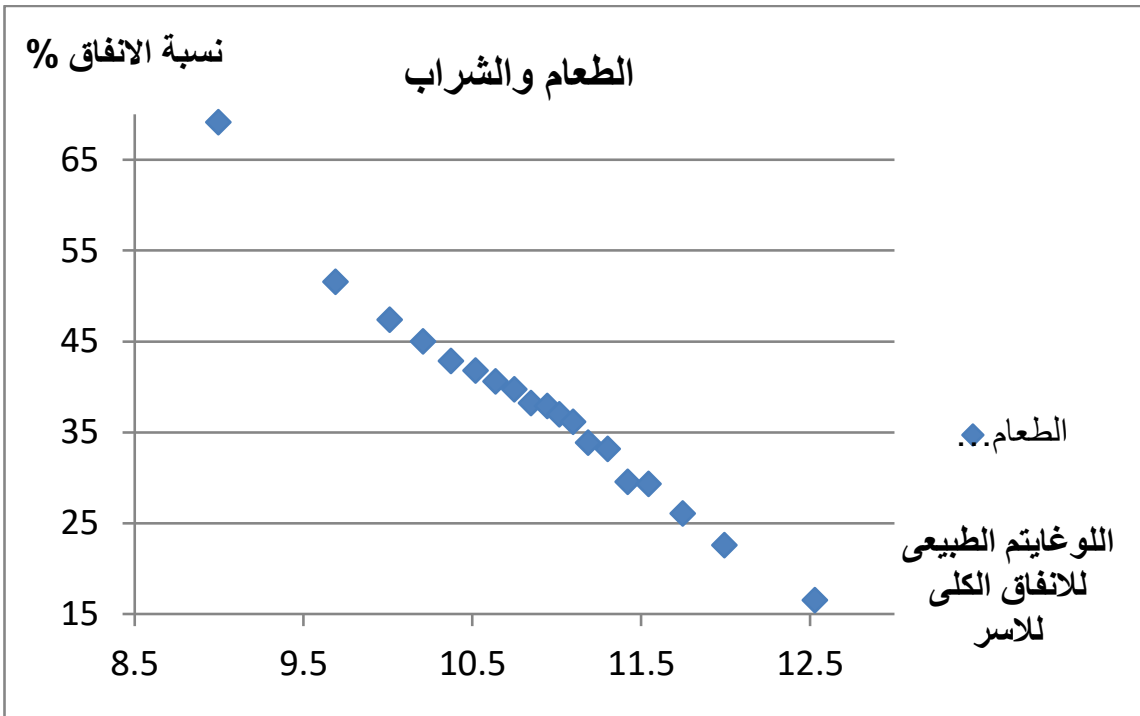

شكل 1. الثكل الانتشاري لنسبة الإنفاق على الطعام والثراب في الحضر

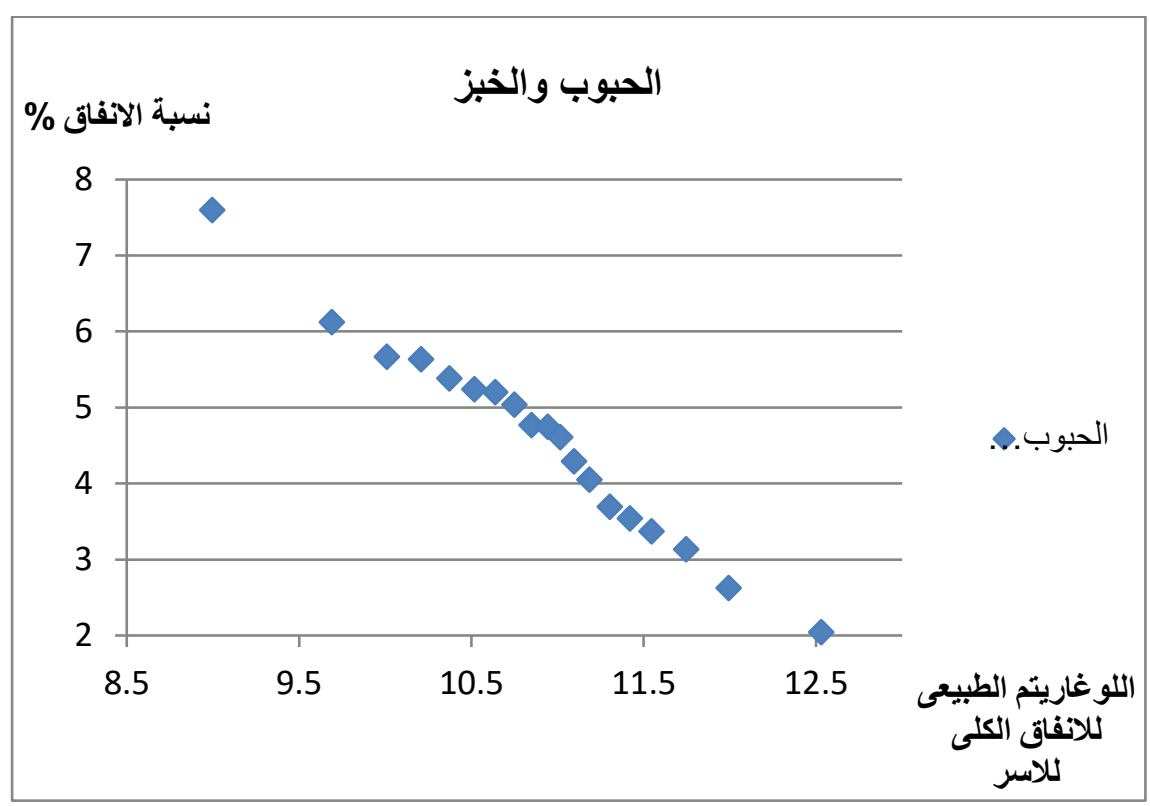

شكل 2. الثكل الانتشاري لنسبة الإنفاق على الحبوب والخبز في الحضر 


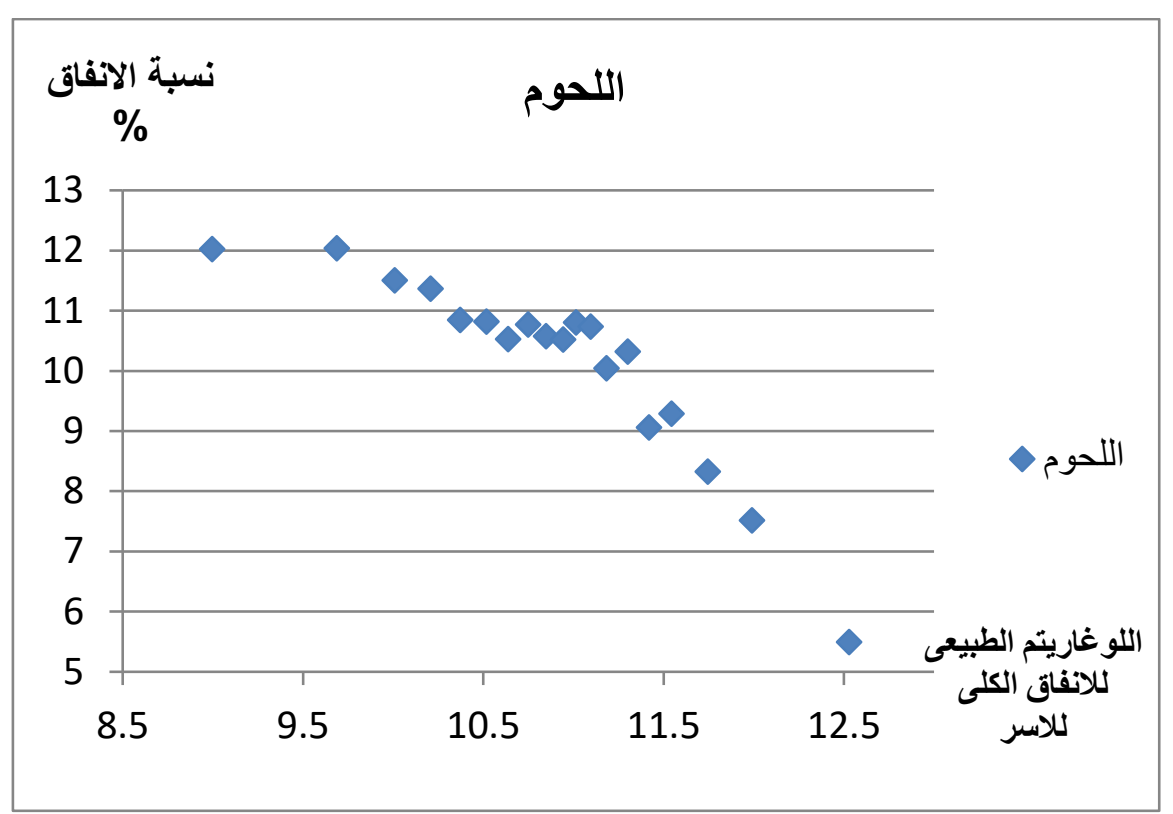

شكل 3. الشكل الانتشاري لنسبة الإنفاق على اللحوم في الحضر

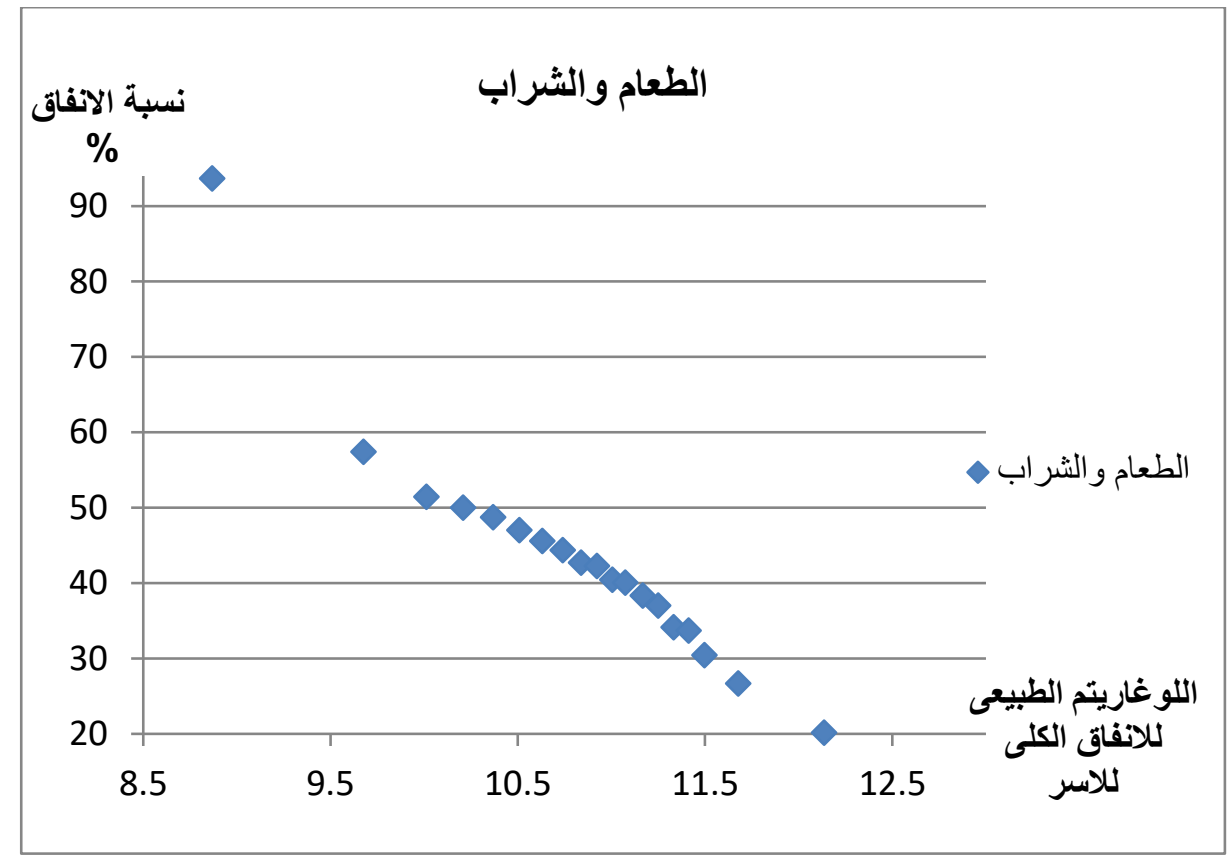

شكل 4. الثكل الانتشاري لنسبة الإنفاق على الطعام والثراب في الريف 


$$
\text { منة الله - العراقي - قنديل }
$$

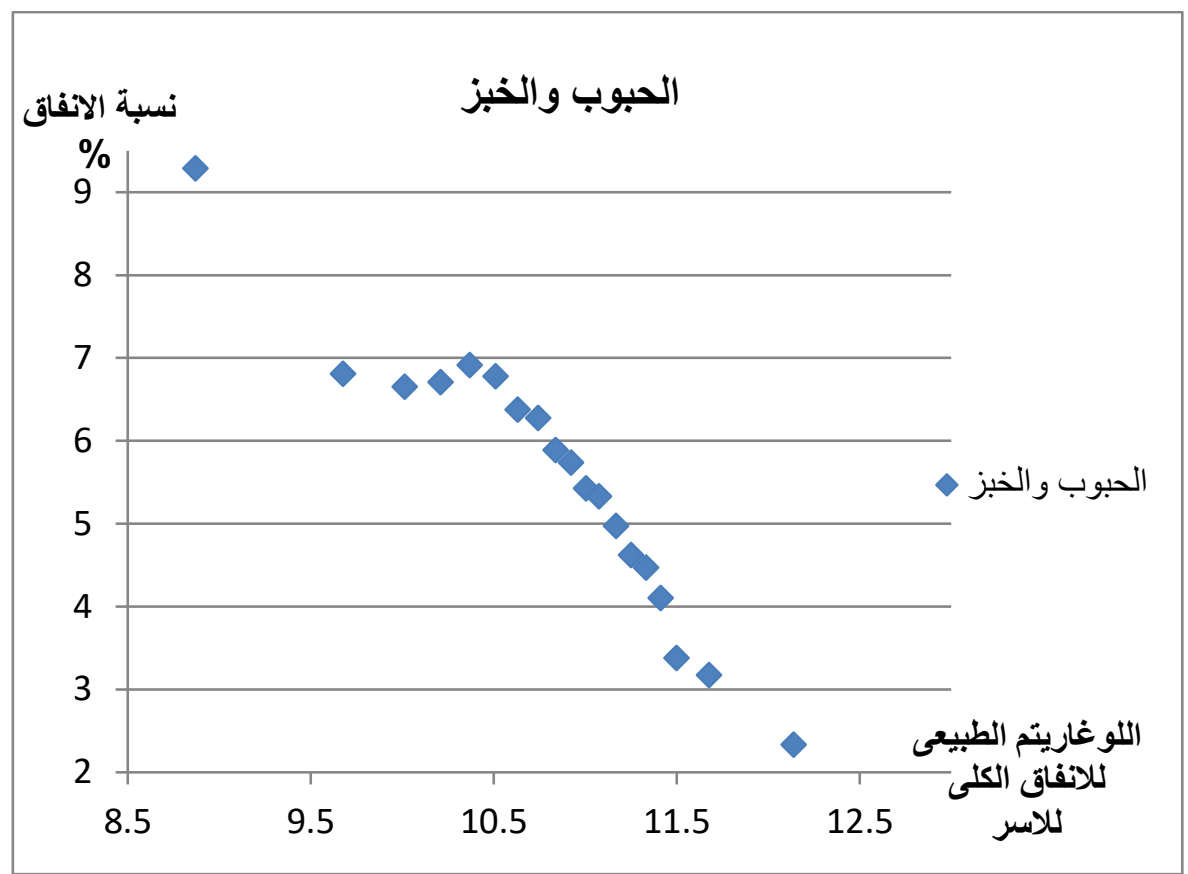

شكل 5. الثكل الانتشاري لنسبة الإنفاق على الحبوب والخبز في الريف

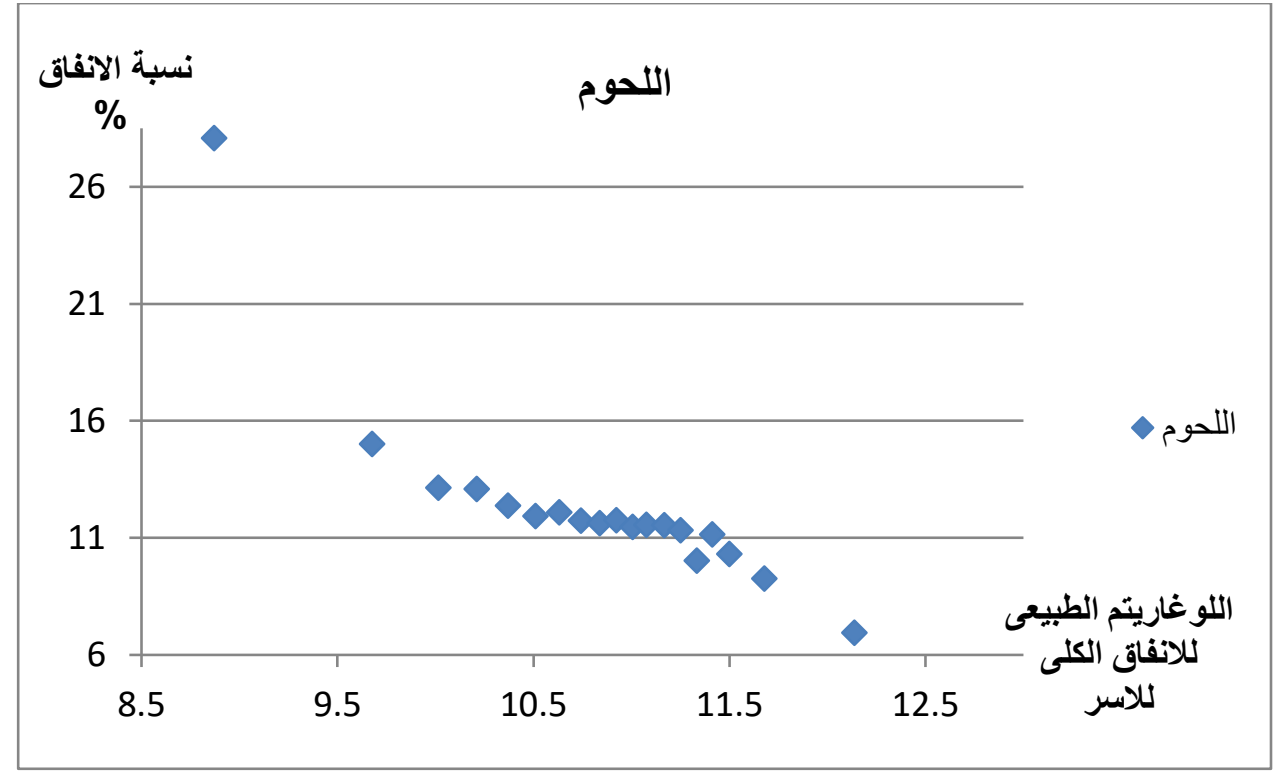

شكل 6. الثكل الانتشاري لنسبة الإنفاق على اللحوم في الريف 
علاقة طردية بين كل من لوغاريتم إنفاق الأسرة السنوي

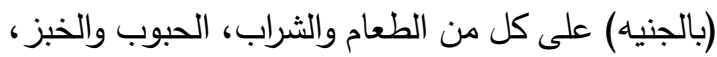

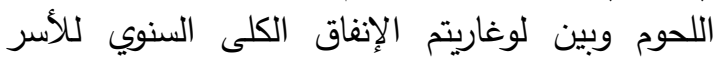
الريفية، ويتبين من الجدولين 13، 14 الأنفات أن مجموعة النين

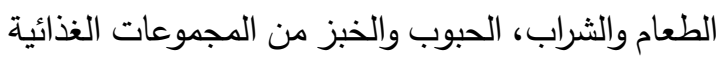

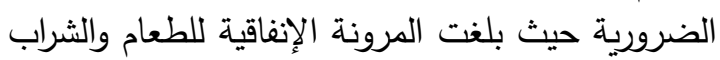

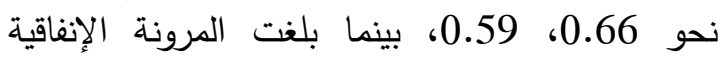

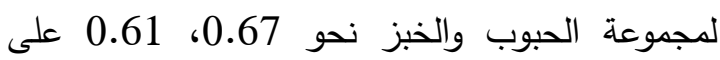

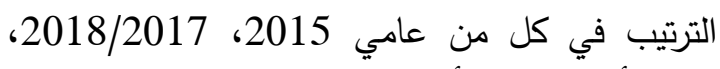

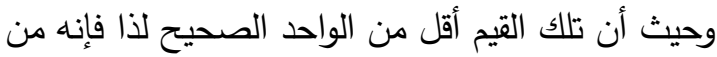

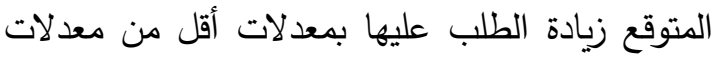

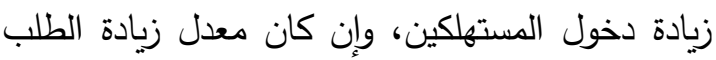

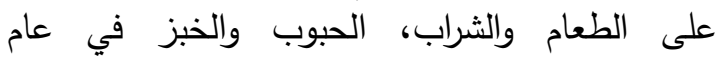

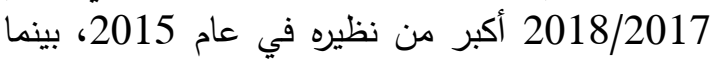
تعتبر مجموعة اللحوم من السلع الغذائية الضرورية في في في

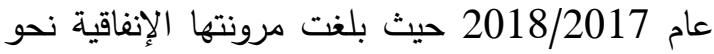

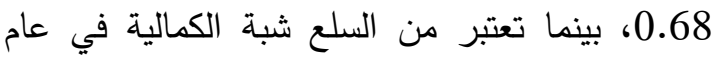

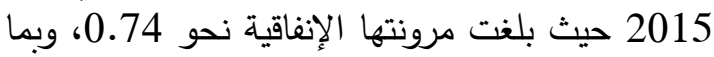

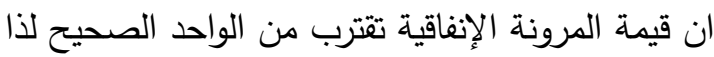

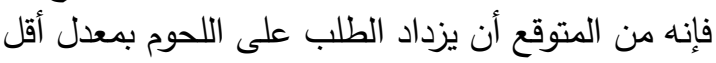
قليلا من معدل زيادة دخول المستهلكين.

7.5 المقارنة بين نتائج نموذج ووركنج ونتائج النموذج اللوغاريتمي المزدوج ويوضح الجدول 15 المقارنة بين المرونات الإنفاقية

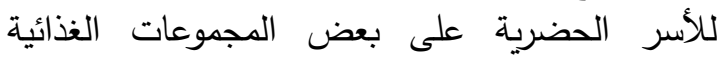
باستخدام نموذج ووركنج وباستخدام النموذج اللوغاريتمي لإني

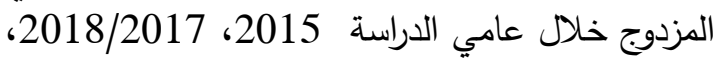

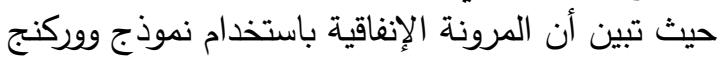

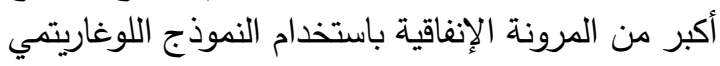

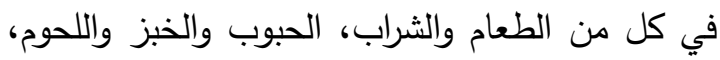
حيث بلغت المرونة الإنفاقية للطعام والثراب باستخدام

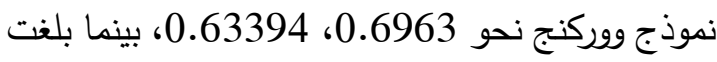
نحو 0.66، 0.63 باستخدام النموذج اللوغاريتمي

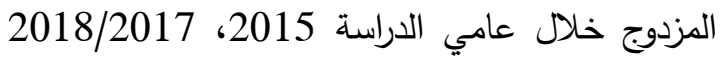
على الترتيب، وقد بلغت المرونة الإنفاقية للحبوب والخبز

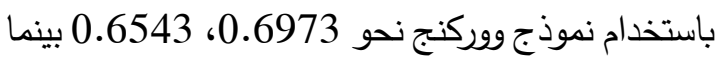
بلغت نحو 0.65، 0.63 باستخدام النموذج اللوغاريتمي
وتكون المرونة الإنفاقية كالآتي:

$$
e_{i}=\beta_{i}
$$

$$
\text { حيث أن : e e }
$$

يوضح الجدولين 11، 12 نتائج المعادلات الانحدارية والمرونات الإنفاقية للمجموعات الغذائية باستخدام النموذج اللوغاريتمي المزدوج خلال الإنية عامي 2015، 2018/2017، حيث يتبين وجود علاقة طردية

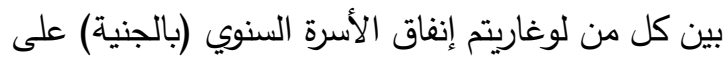

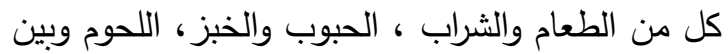

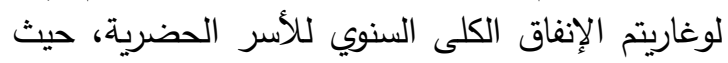

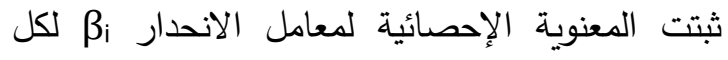

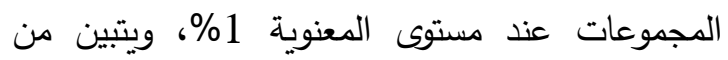

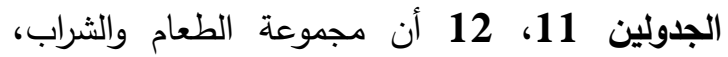

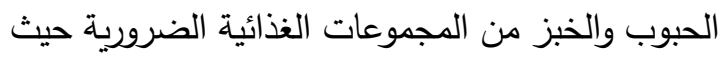

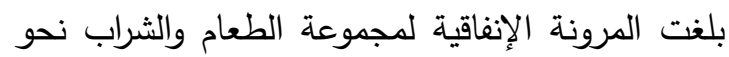

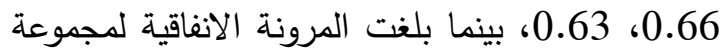
الحبوب والخبز نحو 0.65، 0.63، 0.63 في كل من الن عام

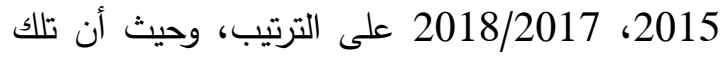
القيم أقل من الواحد الصحيح لذا فإنه من المتوقع زيادة

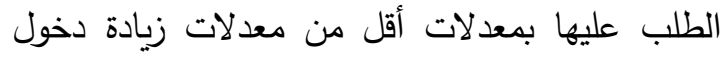
المستهلكين، وإن كان معدل زيادة الطلب على على الطعام

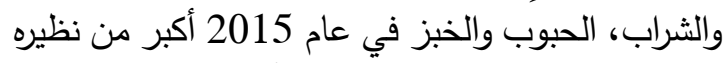

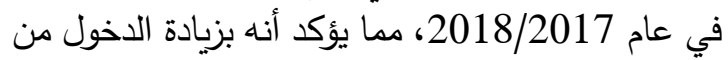
عام لأخر تتخفض نسبة ما ينفق على الطعام والشراب،

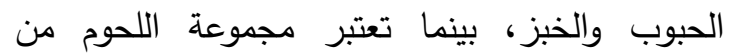

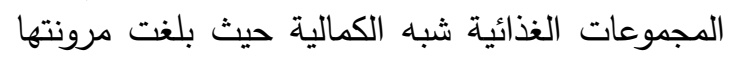
الإنفاقية نحو 0.78 ، 0.81 في كل من عام 2015، الثبه 2018/2017 على الترتيب، وبما أن قيمة المرونة

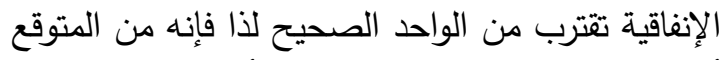

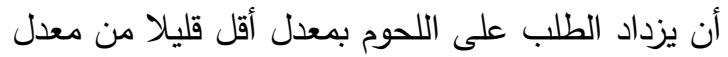
زيادة دخول المستهلكين.

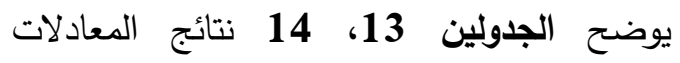
الانحدارية والمرونات الإنفاقية للمجموعات السلعية، التي

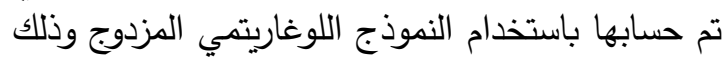
خلال عامي 2015، 2018/2017، حيث يتبين وجود النودئ 
جدول 11. المعادلات الانحدارية والمرونات الإنفاقية على المجموعات السلعية والإنفاق الكلى لأسر الحضر لعام 2015

\begin{tabular}{|c|c|c|c|}
\hline المجموعة السلعية & المعادلة & $R^{2}$ & المرونة الانفاقية \\
\hline الطعام والثراب & $\begin{array}{c}\operatorname{Lny}=2.45+0.66 \operatorname{Ln} X \\
(10.42)^{*}(29.04)^{*}\end{array}$ & 0.98 & 0.66 \\
\hline الحبوب والخبز & $\begin{array}{c}\operatorname{Lny}=0.37+0.65 \operatorname{Ln} X \\
(1.11)^{*}(19.90)^{*}\end{array}$ & 0.96 & 0.65 \\
\hline 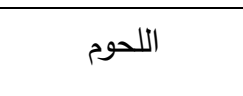 & $\begin{array}{c}\operatorname{Lny}=-0.03+0.78 \operatorname{Ln} X \\
(-0.11)^{*}(30.42)^{*}\end{array}$ & 0.98 & 0.78 \\
\hline
\end{tabular}

حيث ان : Iny = لوغاريتم إنفاق الأسرة السنوي على السلعة (بالجنيه).

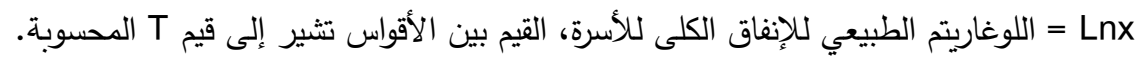

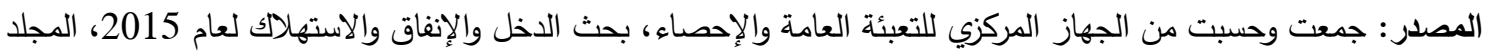

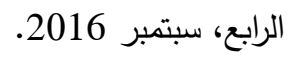

جدول 12. المعادلات الانحدارية والمرونات الإنفاقية على المجموعات السلعية والإنفاق الكلى لأسر الحضر لعام 2018/2017

\begin{tabular}{|c|c|c|c|}
\hline المجموعة السلعية & المعادلة & $R^{2}$ & المرونة الانفاقية \\
\hline الطعام والثراب & $\begin{array}{c}\text { Lny }=3.02+0.63 \operatorname{LnX} X \\
(14.45)^{*}(32.91)^{*}\end{array}$ & 0.98 & 0.63 \\
\hline الحبوب والخبز & $\begin{array}{c}\operatorname{Lny}=0.86+0.63 \operatorname{Ln} X \\
(3.32)^{*}(26.7)^{*}\end{array}$ & 0.98 & 0.63 \\
\hline 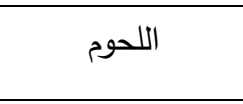 & $\begin{array}{c}\operatorname{Lny}=-0.21+0.81 \operatorname{Ln} X \\
(-0.67)^{*}(28.37)^{*}\end{array}$ & 0.98 & 0.81 \\
\hline
\end{tabular}

حيث ان : Iny = لوغاريتم إنفاق الأسرة السنوي على السلعة (بالجنيه).

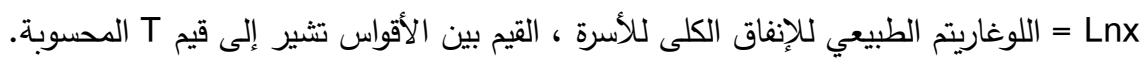

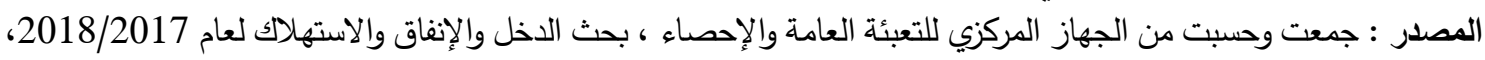
المجلد الرابع ، يونيو 2019

جدول 13. المعادلات الانحدارية والمرونات الإنفاقية على المجموعات السلعية والإنفاق الكلى لأسر الريف لعام 2015

\begin{tabular}{|c|c|c|c|}
\hline المجموعة السلعية & المعادلة & $R^{2}$ & المرونة الانفاقية \\
\hline الطعام والثراب & $\begin{array}{c}\operatorname{Lny}=2.59+0.66 \operatorname{LnX} X \\
(8.63)^{*}(22.61)^{*}\end{array}$ & 0.97 & 0.66 \\
\hline الحبوب والخبز & $\begin{array}{c}\operatorname{Lny}=0.31+0.67 \operatorname{Ln} X \\
(0.66)^{*}(14.86)^{*}\end{array}$ & 0.92 & 0.67 \\
\hline 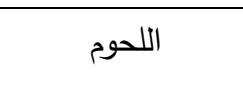 & $\begin{array}{c}\operatorname{Lny}=0.61+0.74 \operatorname{Ln} X \\
(2.35)^{*}(29.10)^{*}\end{array}$ & 0.98 & 0.74 \\
\hline
\end{tabular}

حيث ان: Iny = لوغاريتم إنفاق الأسرة السنوي على السلعة (بالجنيه).

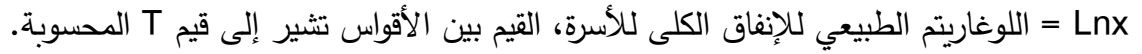

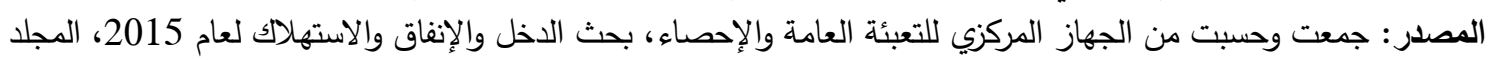
الرابع، سبتمبر 2016. 
جدول 14. المعادلات الانحدارية والمرونات الإنفاقية على المجموعات السلعية والإنفاق الكلى لأسر الريف لعام 2018/2017

\begin{tabular}{|c|c|c|c|}
\hline المجموعة السلعية & المعادلة & $R^{2}$ & المرونة الانفاقية \\
\hline الطعام والشراب & $\begin{array}{c}\operatorname{Lny}=3.49+0.59 \operatorname{Ln} X \\
(13.45)^{*}(24.74)^{*}\end{array}$ & 0.97 & 0.59 \\
\hline الحبوب والخبز & $\begin{array}{c}\operatorname{Lny}=1.29+0.61 \operatorname{Ln} X \\
(2.66)^{*}(13.62)^{*}\end{array}$ & 0.92 & 0.61 \\
\hline اللحوم & $\begin{array}{c}\operatorname{Lny}=1.29+0.68 \operatorname{Ln} X \\
(3.68)^{*}(21.19)^{*}\end{array}$ & 0.96 & 0.68 \\
\hline
\end{tabular}

حيث ان : Iny = لوغاريتم انفاق الاسرة السنوي على السلعة (بالجنيه)

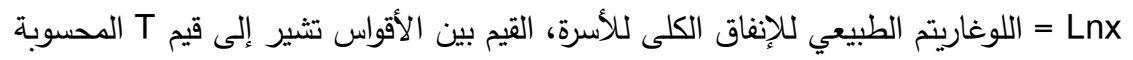

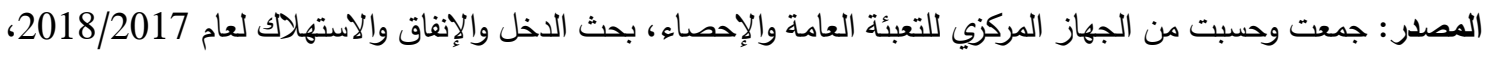
المجلد الرابع، يوليو 2019

جدول 15. المرونات الانفاقية على المجموعات السلعية في الحضر عامي 2015 ، 2018/2017

\begin{tabular}{|c|c|c|c|c|}
\hline \multicolumn{2}{|c|}{ نموذج اللوغاريتمى المزدوج } & \multicolumn{2}{|c|}{ نموذج ووركينج } & \multirow{2}{*}{ المجموعة الغذائية } \\
\hline $2017 / 2018$ & 2015 & $2017 / 2018$ & 2015 & \\
\hline 0.630 & 0.660 & 0.639 & 0.696 & الطعام والثراب \\
\hline 0.630 & 0.650 & 0.654 & 0.697 & الحبوب والخبز \\
\hline 0.810 & 0.780 & 0.828 & 0.806 & اللحوم الحوم \\
\hline
\end{tabular}

المصدر : جمعت من الجداول أرقام ( 9 ، 11 ، 12 ).

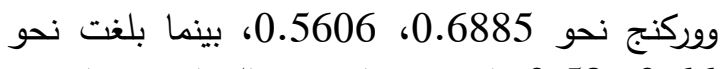
0.66، 0.59 باستخدام النموذج اللوغاريتمي المزدوج

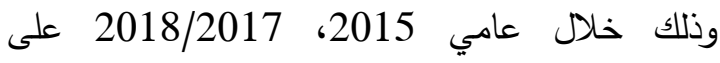
الترتيب، وقد قدرت المرونة الإنفاقية للحبوب والخبز

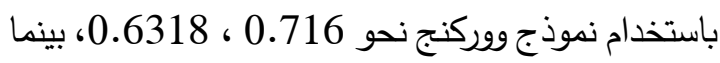
بلغت نحو 0.67، 0.61 باستخدام النموذج اللوغاريتمي

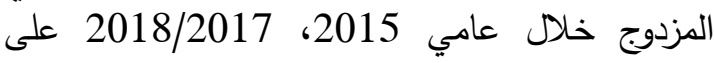
الترتيب، وقد بلغت المرونة الإنفاقية للحوم باستخدام

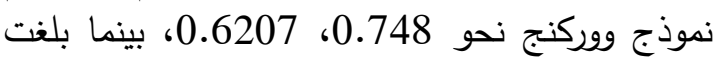
المرونة الإنفاقية للحوم باستخدام النموذج اللوغاريتمي المزدوج نحو 0.74، 0.68 خلال الإنغانة عامي الدراسة 2015، 2018/2017 على الترتيب.
المزدوج خلال عامي 2015، 2018/2017 على والثى الترتيب، وبلغت المرونة الانفاقية للحوم باستخدام نموذج

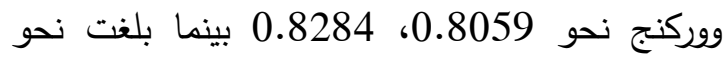
0.78، 0.81 باستخدام النموذج اللوغاريتمي المزدوج

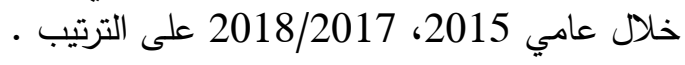
يوضح الجدول 16 المقارنة بين المرونات الإنغاقية للأسر الريفية على بعض المجموعات الغذائية باستخدام

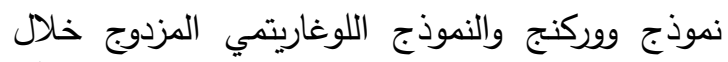

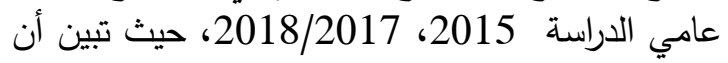

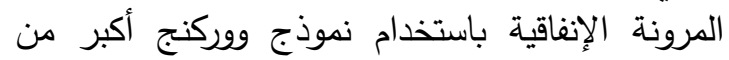

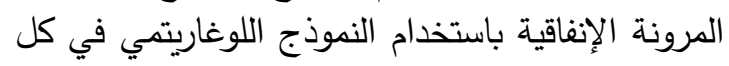

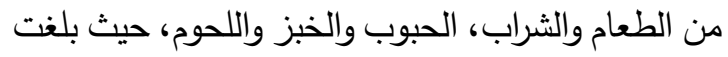

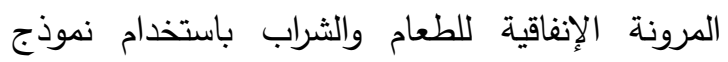




$$
\text { منة الله - العراقي - قنديل }
$$

جدول 16. المرونات الانفاقية على المجموعات السلعية في الريف عامي 2015 ، 201/2017

\begin{tabular}{|c|c|c|c|c|}
\hline \multicolumn{2}{|c|}{ نموذج اللوغارتيمى المزدوج } & \multicolumn{2}{|c|}{ نموذج ووركينج } & \multirow{2}{*}{ المجموعة الغذائية } \\
\hline $2017 / 2018$ & 2015 & $2017 / 2018$ & 2015 & \\
\hline 0.590 & 0.660 & 0.561 & 0.689 & الطعام والثراب \\
\hline 0.610 & 0.670 & 0.632 & 0.716 & الحبوب والخبز \\
\hline 0.680 & 0.740 & 0.621 & 0.748 & 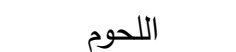 \\
\hline
\end{tabular}

الجهاز المركزي للتعبئة العامة والإحصاء (2019) بحث الدخل والإنغاق والاستهلاك لعام 2018/2017، المجلد

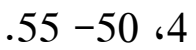

محمد بدير العراقي، حسين سرحان (2017) التضخم

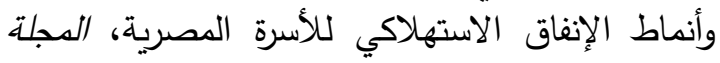

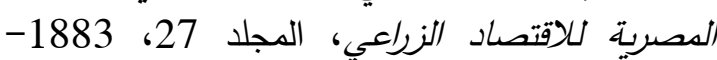
.1892

مصطفى عبد ربه القبلاوي، هبة الله السيد 2015) دراسة

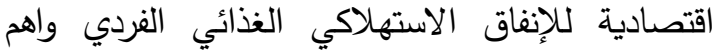

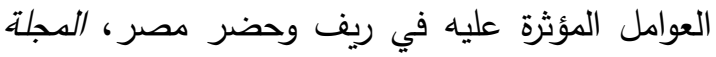
الدصرية للاقتصاد الزراعي، المجلد 25، 684- 696 فئ

ثانياً: المراجع الإنجليزية

Working, H (1943) "Statistical Laws of Family Expenditure", Journal of the American Statistical Association, 38, 4356.

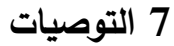

تشير النتائج إلى ان نصيب الغذاء في ميزانية الأسرة الريفية الفقيرة ارتفع من 53.7\% عام 2015 إلى فئ فئ

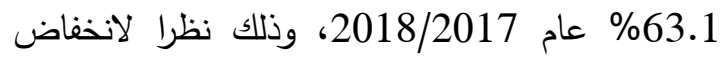
الاخل الحقيقي للأسرة من جراء برنامج الإصلاح الاقتصادي وبالمثل إرتفع نصيب الغذاء من ميزانية الإهن

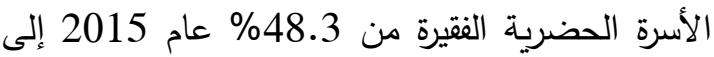
53.3\% عام 2018/2017، وفى هذا الإطار أيضا توضح النتائج انخفاض المرونة الإنفاقية للأسرة الريفية الفقيرة من 75.0\% عام 2015 إلى 69.0\% عام النقائ 2018/2017 أي أن الغذاء أصبح أكثر ضرورية نظرا لانخفاض الدخل الحقيقي للأسرة الريفية خلال فترة تطبيق الغناء برنامج الإصلاح الاقتصادي هذا وتوصنى الدراسة باستخدام نموذج ووركنج في تحليل بيانات ميزانية الأسرة لاعتباره أكثر ملائمة لتحليل السياسات الاقتصادية للأسرة ولأنه يعطى نتائج ممتازة كما توضح الأشكال الانتشارية والتقديرات الإحصائية.

\section{المراجـع}

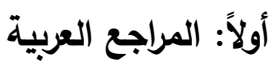

الجهاز المركزي للتعبئة العامة والإحصاء (2016) بث الدخل والإنغاق والاستهلاك لعام 2015، المجلد

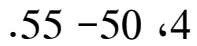




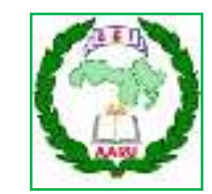

Arab Univ. J. Agric. Sci., Ain Shams Univ., Cairo, Egypt

29(1), 115 - 131, 2021

Website: http://ajs.journals.ekb.eg

131 DOI: 10.21608/ajs.2021.55400.1322

\title{
Changes in Food Expenditures in Urban and Rural Egypt
}

\author{
Mennat-Allah M Hassan*, Mohamed B El-Eraky, Mohamed S Qandil \\ Agric. Economics Dept, Fac of Agric, Ain Shams Univ, P.O. Box 68, Hadayek Shoubra \\ 11241, Cairo, Egypt
}

[7]

* Corresponding author: menammdouh26@gmail.com

Received 3 January, $2021 \quad$ Accepted 22 March, 2021

\begin{abstract}
The aim of this research is to trace recent changes in family expenditures on food commodities between 2015 and 2017/18. The data is drawn from CAPMAS publications on family income, expenditure, and consumption for both years. Three food groups are explored in this paper: 1- The aggregate group of food and beverages; 2-The grains and bread group; and 3 - The meat group. Two statistical models are utilized for the purposes of data analysis. The first model is known as Working's model and the second model is the well-Known double logarithmic model. The analysis shows that the expenditure elasticity of the aggregate group of food and beverages ranges between 0.423 for high-income urban families in 2017/18 to 0.763 for urban poor families in 2015. For rural families the same elasticity is about 0.313 for high-income families in 2017/18 and about 0.751 for poor families in 2015. These
\end{abstract}

estimates are derived from the OLS estimates of Working's model. The double logarithmic model gives one single estimate for expenditure elasticity for the entire set of data. For example, the expenditure elasticity for all families in 2017/18 is 0.63 in urban areas and 0.59 in rural areas according to the double logarithmic model. The same estimates are 0.64 for urban areas and 0.56 for rural areas according to Working's model. The Working's model fits the family survey data quite well and gives multiple estimates of expenditure elasticity according to the level of family income. In contrast, the double logarithmic model gives one estimate of expenditure elasticity that does not change with the level of family income. That is Working's model would be more suitable for policy analysis purposes.

Keywords: Spending, Depreciation, Regression, Elasticities, Working, Subsidies 